\title{
THE IMPACT OF OIL PRICE FLUCTUATIONS ON THE ECONOMIES OF ENERGY PRODUCING STATES: COMMENT
}

\author{
M. Ray Perryman*
}

\section{Introduction}

This paper provides a brief assessment of a more extensive analysis, which is being published contemporaneously, by Professor Gary Hunt. In his very useful consideration of the oil price transmission mechanism, Professor Hunt examines the impact of recent oil price shocks on business activity in three states, Colorado, Oklahoma, and Wyoming, that are characterized by substantial dependence on petroleum extraction and related sectors. The paper represents an excellent initial effort in illustrating oil price linkages to aggregate economic performance. In fact, the only substantial deficiency in Professor Hunt's analysis is merely one of degree. The models are carefully specified and estimated. Unfortunately, however, the highly simplified systems utilized in the investigation simply are not sufficiently detailed to permit a comprehensive assessment of the channels through which impacts of this nature are operative. This task can only be meaningfully accomplished through the specification and empirical determination of a very comprehensive econometric system for the relevant region. The author has developed such a structure for the Texas economy over the course of the past ten years. This multimillion equation model of a large petroleum-based economy provides a thorough integration of oil price movements into the overall stream of business performance. The remainder of this analysis focuses on a few of the primary components of this complex transmission mechanism.

\section{The Oil Price Transmission Mechanism}

As Professor Hunt specifies in a simplistic format, the most obvious channel through which world petroleum prices affect aggregate economic performance is through the direct impact on oil and gas extraction (generalized to mining in his analysis). It must be noted, however, that within the dynamic context of this market, a drop in the observed price is typically accompanied by a corresponding decline in production costs (equipment rental rates, labor costs, severance taxes, etc). Consequently, the optimal price variable to incorporate into a properly specified system is the "spread" between the quoted rate per

\footnotetext{
*Herman Brown Professor of Economics and Director of the Center for the Advancement of Economic Analysis, Baylor University
}

barrel and the cost per barrel. This modification, which has substantial empirical significance, was not embodied in Professor Hunt's analysis.

Other more obvious channels of direct influence include impacts on output, income received, and employment in the fabricated metal manufacturing (pipe) sector, the nonelectrical machinery (drilling rigs) sector, the petroleum refining and petrochemical sectors, and the pipeline transportation sector. At the highly aggregated level of Professor Hunt's analysis, these mechanisms are either omitted or, alternatively, considered in a context which permits offsetting tendencies in other industries to camouflage total effects. For example, several categories of manufacturing in Texas, such as electronics and aerospace, have been experiencing rapid growth rates throughout the debacle in the oil industry over the past few years. Thus, an investigation which considers manufacturing as a composite sector is inherently incapable of tracing all elements of the petroleum impact.

In addition to these obvious linkages, several additional influences are systematically operative in oil producing states. The governmental sector, for example, is directly impacted by reduced collections of oil and gas severance taxes and indirectly affected by lower sales and/ or income tax collections and greater demands for services (unemployment compensation, welfare, etc.). The financial sector is directly damaged through its portfolio of energy loans, which is normally substantial in an oilproducing state. Many business service entities, including direct oilfield services, engineering firms, law firms, and accounting firms, depend on the petroleum industry for their livelihood. A major portion of the heavy construction (SIC 10) industry in oil-producing regions is typically involved in oilfield construction.

As a final point of departure, a number of complex "income-substitution" effects are generated by falling petroleum prices. Gains in real disposable income from declining prices must be balanced against declining incomes generated by layoffs and shutdowns. Lower fuel costs for electric utilities stimulate consumption, while reduced industrial activity depresses demand. The transportation sector undergoes a similar phenomenon. Aggregate income and sales are impacted by counterveiling forces, with the outcome being theoretically ambiguous. A recent series of short-term and long-term simulations of the Texas Econometric Model reveals that the net impact of a major oil price reduction is negative in all major productive categories except agriculture. Moreover, the 
regional impacts within various states are highly variable. In Texas, for example, the Gulf Coast, East Texas, and West Texas areas are influenced directly and immediately by fluctuations in world oil prices due to the nature of their industrial complex. Dallas-Ft. Worth, Austin, and San Antonio, on the other hand, experience more modest, slower, and indirect effects. As an added measure of complexity for Texas, the vast border economy is affected through the direct channels which are functional in Mexico. It is apparent that efforts to gain a complete picture of the multifaceted manner in which world petroleum prices affect the economy of a state with substantial oil-related business activity can only hope to succeed within the context of a large, integrated structural system including detailed industrial and regional specifications and relevant international linkages.

\section{Summary}

This paper offers a comment on the recent work of Professor Gary Hunt and seeks to elucidate briefly a framework for considering many of the channels through which oil prices can impact a regional economy. As noted at the outset, Professor Hunt gives a reasonable, but constrained, assessment of oil price responses across three states. It is a good effort which is well worthy of reading. In the final analysis, however, the descriptive material presented herein provides sufficient evidence to demonstrate that a truly comprehensive empirical assessment of the impact of oil price shocks in energy sensitive regional economies can be meaningfully achieved only within the broader analytical framework afforded by a fully specified econometric system with disaggregated sectoral and regional components. 